\title{
Drug utilization review of oral forms of benzodiazepines in a Belgian 635-bed teaching hospital
}

\author{
- N. Petit, J.-P. Delporte, M. Ansseau, A. Albert and F. Jeusette
}

\section{Introduction}

Comparative studies have shown that Belgium [1], in particular the Liège area [2], is one of the countries with the highest rate of benzodiazepine consumption. High rates of benzodiazepine prescription and utilization in hospitals, and the influence of sex and age were previously reported [3-6]. The potential role of hospitalization in initiating benzodiazepine consumption after discharge was also previously discussed [7-9].

The present study was designed to establish a chart of the consumption of benzodiazepines administered orally in a 635-bed teaching hospital, in Liège, Belgium. Other objectives were to determine the influence of patient-related parameters like sex and age, and of hospital-related parameters (type of services, ward prescription habits, etc.) on benzodiazepine utilization, and finally to assess to which extent benzodiazepine consumption habits can be induced by hospitalization. The study was mainly oriented towards the utilization of benzodiazepines administered orally because we wanted to focus more on the 'conscious' intake of benzodiazepine, as observed in most clinical situations, than on the 'unconscious' intake when they are parenterally administered during technical acts (surgery, endoscopy, interventional radiology, etc.) or, at a transitory step, in intensive care units (ICU). However, in order to assess an overall consumption of benzodiazepines in this hospital, a rough estimation of parenteral utilization is also given.

\section{Methods}

The study received prior approval from the Ethics Committee of the University Hospital in accordance with the 1983 Helsinki Declaration. Patient-related data (age, sex, ward, length of stay) and benzodiazepine consumption-related data (type of medication, dosage, regimen, length and profile of treatment) were collected from 4,307 patient drug records (nearly $20 \%$ of yearly in-patient records) during four periods in 1991 (February, May, August and November). All consecutive record forms for all patients included in the study were surveyed from the admission to the discharge. Data were collected using software developed by the pharmacy department. Data were analysed using Student's t-test, chi square test and analysis of variance. A value of $p<0.05$ was considered to be statistically significant.

The proportion of patients exposed to benzodiazepines before admission was evaluated from medication profiles and medical records, assuming that a patient who used benzodiazepines before admission, would be provided with a benzodiazepine prescription at the beginning of the hospitalization. A random sample of fifty medical records of patients having received a benzodiazepine prescription on the first day of the stay were selected and medi-
Perit N, Delportel P, Anssech M. Abert A Teuselle f Drug Whization review of ord forms of benzodlazepines in a Betglon

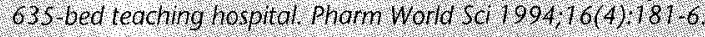

N. Petit and ). P. Delporte (correspondence), Department of Pharmacy, University Uospital, B 4000 Lege, Belgium. M. Ansseau, Department of Psy chiatry. Unversity Hospital, B. 4000 Liege.

A. Albert and F leusette Depatiment of Medical Statistics. Uhiversity Hosplal, 8 - 4000 lege.

\section{Keywords}

Benzodiazepines

Data collection

Dnug utilization

Hospitals

Prescription, drugs

\section{Abstract}

A relrospective study based or 4,30 \% drug partient records was designed to establish a chart of the consumption of benzodiazephes dininistered orally in a 635 bed teaching hospital and to deternine the nfluence of patent related parameters (age, sex) and hospital-related parameters (type of services, prescript on habits, etc. on benzodiazepine utilzation Another objective was to evaluate to which extent benzodizepine consumplion can be nduced by hospitalization a ninor but statistically significant difference $(\mathrm{\rho}<0.05)$ was observed between the proportion of nale $(42.70)$, nd fenale $(46.5 \%$ ) users. Bbsides, when evaluating the consumption h number of defined daily. dases per 100 beddays, there was ittle difference between the consumption of nale $(512$ defined dally doses per 100 beddays) ahd female ( 52.8 defined daily doses per. 100 beddays) patients. A significant rilluence of ace was also observed with an hcrease of benzodiazepine use for patierts aged lom 15 20 10 40-45. lollowed by a progressive decrease for hgher ages. Will hypholics, no peak of consumption related to age was observed but an Thcrease of consunption tron age 1520 10 30.35 . For higher ages the consumption of hypnotics was nearly stable or rising slowly ligh variations in benzodiazepine utization were recorded between hosplal wards ( nedian. 50.77 defined daly doses per 100 beddays. range 0.23 .263 .9 ) I nally, It was tound that $6.8 \%$ of patients with a benzodiazephe treathent inilated durng hosphtalization nay be considered as polenlial berzodiarephie consumers arer disharge

Accepted Febrary 1994 
Table 1 Population and benzodiazepine prescription data during the study periods based on 4,307 patient records

\begin{tabular}{|c|c|c|c|c|c|c|c|c|c|c|c|c|c|}
\hline Word & Numb & of po & $t^{*}$ & Number & f bedday & & $\begin{array}{l}\text { Mear } \\
\text { stay }\end{array}$ & gth of & $\begin{array}{l}\text { Patier } \\
\text { benzo } \\
\text { presc }\end{array}$ & $\begin{array}{l}\text { with } \\
\text { azepin } \\
\text { tion }(\%\end{array}$ & & $\begin{array}{l}\text { Meo } \\
\text { of h } \\
\text { zepi } \\
\text { men }\end{array}$ & $\begin{array}{l}\text { nngth } \\
\text { odia- } \\
\text { reat- } \\
\text { tays) }\end{array}$ \\
\hline & M & $F$ & $M+F$ & M & $F$ & $M+F$ & $M$ & $F$ & M & $F$ & $M+F$ & M & $F$ \\
\hline Medicine & 932 & 757 & 1,683 & 9,769 & 8,715 & 18,484 & 10.5 & 11.6 & 43.8 & 47.0 & 45.2 & 8.1 & 9.2 \\
\hline Surgery & 783 & 573 & 1,356 & 8,018 & 5,627 & 13,645 & 9.8 & 10.1 & 55.6 & 61.4 & 58.0 & 4.6 & 5.0 \\
\hline Mixed & 406 & 284 & 690 & 2,306 & 1,791 & 4,097 & 5.7 & 6.3 & 16.0 & 19.7 & 17.4 & 3.3 & 3.0 \\
\hline care & 317 & 164 & 475 & 1,903 & 1,319 & 3,222 & 6.1 & 8.0 & 43.4 & 43.9 & 43.6 & 4.2 & 5.8 \\
\hline Unknown & 50 & 53 & 103 & 276 & 261 & 537 & 5.5 & 4.9 & 34.0 & 30.2 & 32.0 & 3.1 & 3.6 \\
\hline Total & 2,482 & 1,825 & 4,307 & 22,272 & 17,713 & 39,985 & 9.0 & 9.7 & 42.7 & 46.5 & 44.3 & & \\
\hline
\end{tabular}

tr. female; Mi male.

cations before admission surveyed, in order to roughly estimate the proportion of patients who were benzodiazepine users before admission.

In the same way, induced benzodiazepine consumption after discharge was evaluated from medication profiles and medical records, assuming that a patient who used no benzodiazepines when admitted to the hospital but was discharged with a benzodiazepine prescription, is a potential mediumor long-term consumer. To verify this assumption, a random sample of fifty medical records of patients, non-users at admission but initiated to benzodiazepine usage during the stay up to its end, was surveyed and medications at discharge examined.

Benzodiazepine utilization was evaluated according to anatomical-therapeutical-chemical (ATC) class, distinguishing hypnotics (N05CD) and anxiolytics (N05BA) [10]. The consumption was expressed in defined daily doses (DDD), in DDD per 100 beddays and in number of prescriptions. DDDs of the most used benzodiazepines were compared with calculated mean prescribed daily doses (PDD), determined from drug patient records.

\section{Results}

\section{Population data}

During the four study periods, 4,307 patient records were examined. $2.3 \%$ of these records could not be identified with respect to the ward where the patient had been admitted. The mean age of the patients was 50.2 years. The age distribution was non-gaussian and the median value was 56.0 years. There was no significant difference between the four periods. The overall mean ratio of male to female in-patients was 58/42 and no significant differences were found between the periods, except in August with a ratio of $62 / 38$. The ratio of patients admitted to the various wards (internal medicine, surgery, mixed internal medicine/surgery, and intensive care) was the same during the four periods ( $p>0.05$ ] (Table 1 ). Since no significant differences were observed between the population parameters of the four study periods, most data were combined into a single sample. The average hospital stay was 9.3 days, ranging from 5.9 days in mixed wards to 11.0 days in internal medicine wards $(p<0.05)$.

\section{Influence of patient sex on benzodiazepine prescription}

Regardless of the study periods and wards, there was a small but significant difference between the proportions of male $(42.7 \%)$ and female $(46.5 \%)$ benzodiazepine consumers (Table 2). However, when restricting prescription analysis to hypnotics (N05CD,

Table 2 influence of sex on prescription of benzodiazepines

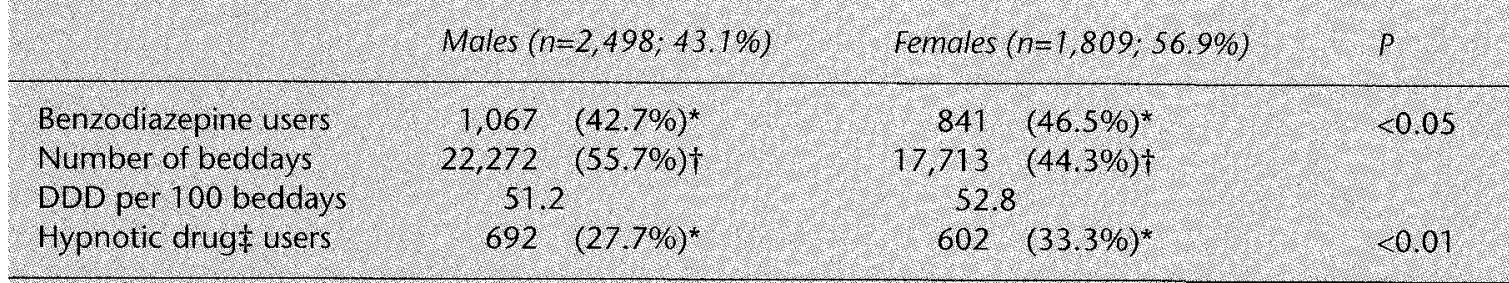

Percentage within group.

tPercentage of total.

tATC Codes NOSCD, No5CF, No5CM. 


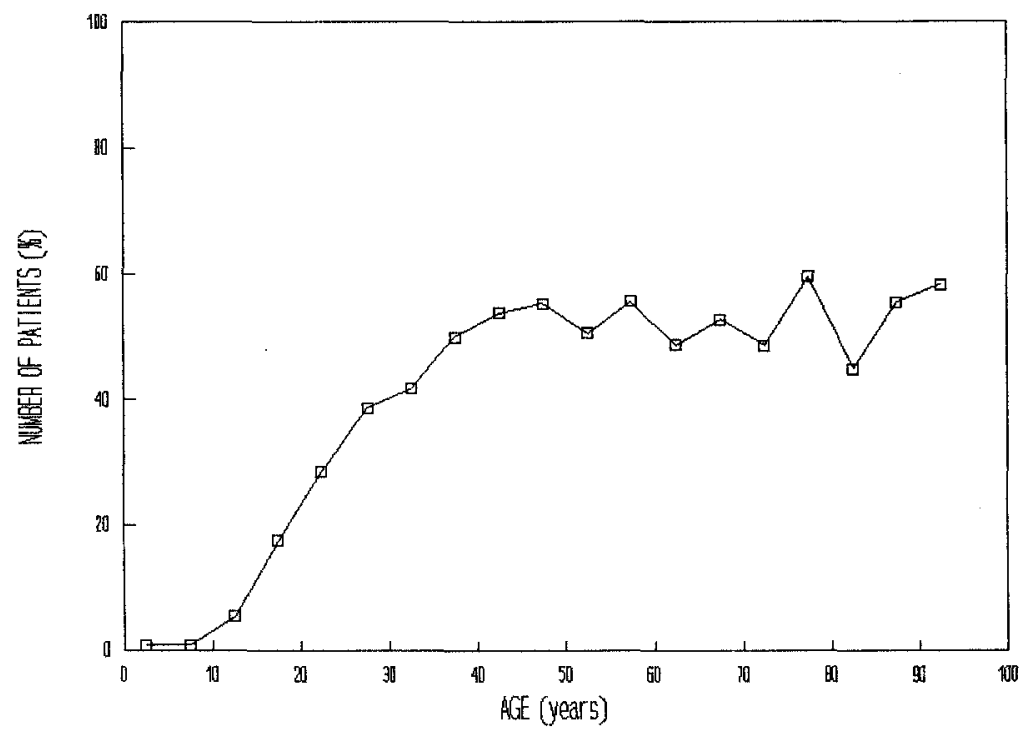

N05CF, N05CM), highly significant sex discrepancies were found: $27.74 \%$ for male and $33.28 \%$ for female users $(p<0.01)$.

\section{Influence of age on benzodiazepine utilization and prescription}

When looking at the prescriptions of oral benzodiazepines with respect to age, there was a progressive increase of the proportion of patients with benzodiazepines, from age 15 to 40 , after which it remained fairly constant (Fig. 1). Benzodiazepine consumptions expressed in DDD per 100 beddays and related to patient age are shown in Figure 2. The overall benzodiazepine consumption was divided according to ATC code, in hypnotics (N05CD) and anxiolytics (N05BA). Because of similar therapeutic activities, classes N05CF (cyclopyrrolones) and N05CM were combined with hypnotics.

On the other hand, a proportion of $28.9 \%$ of the patients were receiving a prescription for benzodiazepines only once, at night. This corresponded to a consumption of 23.45 DDD per 100 beddays. The data relating to this particular group of benzodiazepine users subdivided by age, are presented in Figure 3.

The median value of the age of benzodiazepine consumers was 59 years, higher than the median value of patients admitted.

\section{Influence of the type of ward on benzodiazepine prescription and utilization}

Table 1 shows that $44.3 \%$ of the patients were exposed to oral benzodiazepines during hospitalization. For both male and female patients, the type of ward had a marked influence on benzodiazepine utilization, the highest prescription rate being observed in surgical wards (58\% of users), the lowest in mixed units (internal medicine/surgery) (17.5\%). Benzodiazepine consumption on the different wards, expressed in number of DDD per 100 beddays, is presented in Table 3. The mean value was 59.08 DDD per 100 beddays with an SD of 47.52 DDD per 100 beddays. Large variations were observed between wards, from 0.23 DDD per 100 beddays in paediatry to 263.90 DDD per 100 beddays in the medical psychology unit.

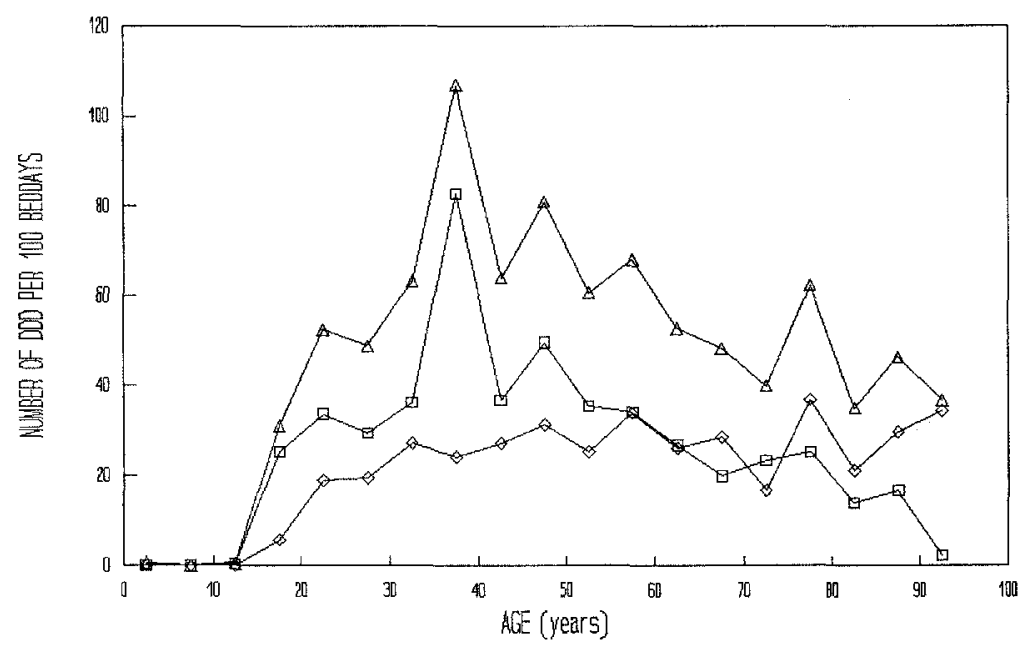

\section{$\Delta$ Figure 2}

Benzodiazepine utilization expressed in number of DDD (defined daily doses) per 100 beddays in relation to age. $\square$ : ATC class NO5BA (anxiolytics); $৩$ : ATC classes N05CD, N05CF, N05CM (hypnotics); $\Delta$ : total 


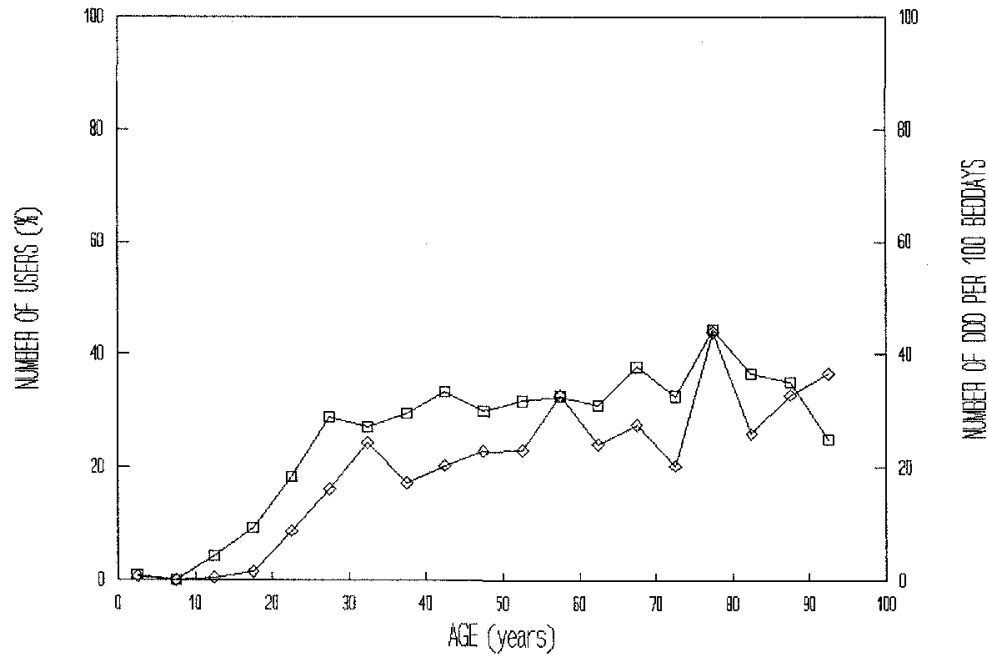

A Figure 3

Proportion of patients provided with one prescription of benzodiazepines at night only, in relation to age. $\square$ : proportion of users; $\diamond: D D D$ per 100 beddays

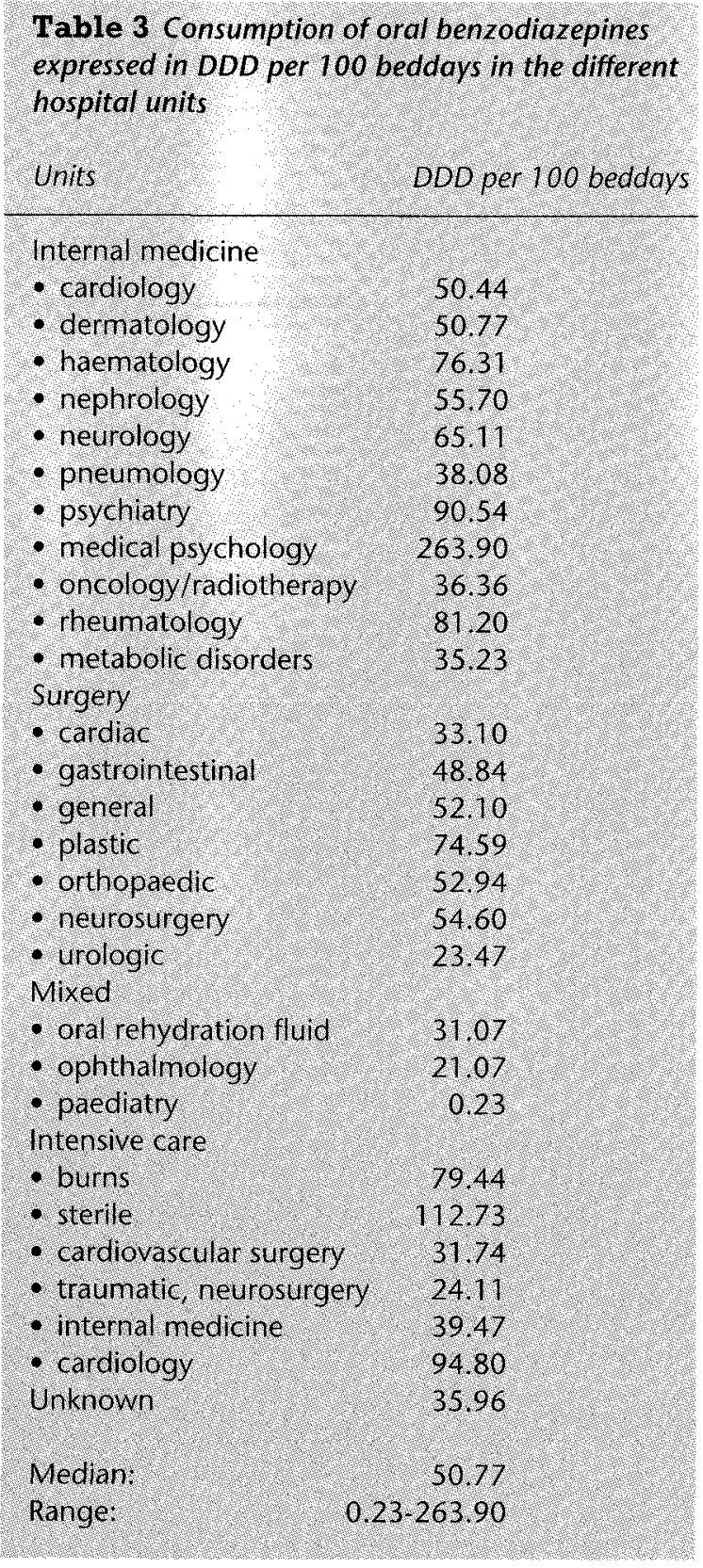

Important variations were also observed within the different groups of wards (medical, surgical, intensive care, etc.). However, by focusing the study only on oral benzodiazepine and neglecting parenteral administration, some bias will affect the consumption data. In addition to the present study, this bias was roughly estimated from another study performed in a 24-day period in 1993, including about 1,300 patient medication records ( 12,801 beddays), without distinctions for patient age and sex. During that period, the consumption of parenteral benzodiazepine (diazepam injection $10 \mathrm{mg}$, midazolam injections 5 and $15 \mathrm{mg}$ ) was measured and estimated at 7.23 DDD per 100 beddays on the wards.

Differences between the consumption of parenteral benzodiazepine in the various types of wards are shown in Table 4. As expected the highest consumption of parenteral benzodiazepine is observed in intensive care units where benzodiazepines are commonly used to obtain sedation and anxiolysis in a few patients.

During the same period, parenteral benzodiazepine consumption adds another 6.48 DDD per 100 beddays to the overall utilization, because of their use during technical interventions like surgery, endoscopy, coronary investigation and dilatation, etc. Although obtained in 1993 these results give valuable complementary information since the quantities of parenteral benzodiazepine supplied by the pharmacy in 1991 and in 1993 are almost equal (12.72 and 12.58 DDD per 100 beddays)

\section{Comparative utilization of the various benzodiazepines}

The total consumption of oral benzodiazepines in the hospital during the study periods was 53.95 DDD per 100 beddays, including 29.29 DDD per 100 beddays of anxiolytics (N05BA) and 24.66 DDD per 100 beddays of hypnotics (N05CD, N05CF, N05CM). Six products, lormetazepam (17.89 DDD per 100 beddays), flunitrazepam (3.20 DDD per 
Table 4 Mean consumption of parenteral benzodiazepines expressed in DDD per 100 beddays in the different types of service

\begin{tabular}{|c|c|c|}
\hline Type of service & Beddoys & $\begin{array}{l}\text { DOD per } \\
100 \text { bedalys }\end{array}$ \\
\hline Internal medicine & 6,868 & 3.80 \\
\hline Surgery & 4,526 & 5.65 \\
\hline Mixed & 1,357 & 8.40 \\
\hline Intensive care & 1,100 & 26.96 \\
\hline
\end{tabular}

\begin{tabular}{|c|c|c|c|c|c|}
\hline \multicolumn{6}{|c|}{$\begin{array}{l}\text { Table } 5 \text { Comparative values of defined daily doses (DDD) and mean } \\
\text { prescribed daily doses (PDD) during the study periods }\end{array}$} \\
\hline \multicolumn{2}{|c|}{ Benzodiazepine } & ATC codes & $D D D(m g)$ & PDD (mg) & $\begin{array}{l}\text { PDD/DDD } \\
\text { ratio }\end{array}$ \\
\hline \multicolumn{2}{|c|}{ Diazepam } & NOSBAO1 & 10.00 & 15.91 & 1.59 \\
\hline \multicolumn{2}{|c|}{ Oxazepam } & NOSBAO4 & 50.00 & 23.00 & 0.46 \\
\hline \multicolumn{2}{|c|}{ Clorazepate } & NOSBAOS & 20.00 & 43.91 & 2.19 \\
\hline \multicolumn{2}{|c|}{ Lorazepam } & NOSBAOG & 2.50 & 2.46 & 0.98 \\
\hline \multicolumn{2}{|c|}{ Bromazepam } & NOSBA08 & 10.00 & 6.45 & 0.64 \\
\hline \multicolumn{2}{|c|}{ Prazepam } & NOSBAT1 & 30.00 & 17.89 & 0.60 \\
\hline \multicolumn{2}{|c|}{ Alprazolam } & NOSBAT2 & 1.00 & 1.15 & 1.15 \\
\hline \multicolumn{2}{|c|}{ Nitrazepam } & $\mathrm{NO}_{5} \mathrm{CDO} 2$ & 5.00 & 4.70 & 0.94 \\
\hline \multicolumn{2}{|c|}{ Flunitrazepam } & NosCDO3 & 1.00 & 1.90 & 1.90 \\
\hline \multicolumn{2}{|c|}{ Triazolam } & NosCDOS & 0.25 & 0.26 & 1.04 \\
\hline \multicolumn{2}{|c|}{ Lormetazepam } & No5CDO6 & 1.00 & 1.79 & 1.79 \\
\hline \multicolumn{2}{|c|}{ Loprazolam } & NosCD11 & 1.00 & 1.40 & 1,40 \\
\hline
\end{tabular}

100 beddays), both considered as hypnotics, alprazolam (8.92 DDD per 100 beddays), diazepam (7.61 DDD per 100 beddays), lorazepam (5.20 DDD per 100 beddays), and clorazepate (3.58 DDD per 100 beddays), classified as anxiolytics, represented $86 \%$ of the benzodiazepine consumption.

\section{Comparison between DDDs and PDDs}

Values of DDDs and PDDs of the various drugs are presented in Table 5. Differences were observed for 8 of the 12 used benzodiazepines. The DDD value underestimated the PDD in 4 of the 6 most used benzodiazepines. This finding reminds one that DDDs have to be considered as physical measure units of consumption and do not reflect the ratio of users when expressed in number of DDD per 100 beddays. The total number of DDD per 100 beddays was 54.05 whilst $43.3 \%$ of patients used benzodiazepine during the study periods.

\section{Benzodiazepine utilization before admission}

Considering the 50 randomly selected patients provided with a benzodiazepine prescription on the first day of hospitalization, the survey of the medical record confirmed that $62 \%$ of them were actually benzodiazepine users before admission. With respect to the study population, nearly $12.6 \%$ of the patients could be considered as benzodiazepine users before admission.

\section{Benzodiazepine prescription at discharge}

Of 50 randomly selected patients, non-users at admission but initiated to benzodiazepine usage during their hospital stay and benzodiazepine users up to discharge, 16 were actually discharged with a prescription of at least one benzodiazepine. Thus, with respect to our study population, it is expected that in about $6.8 \%$ of the patients discharged with a benzodiazepine prescription initiated in hospital, benzodiazepine consumption is induced by hospitalization.

\section{Discussion}

When looking at the overall prescription rate of benzodiazepine, the present study shows that the patient's sex has a significant influence on utilization but, in contrast to results published on consumption in general practice [1 1 2], differences are smaller. When focusing on hypnotic usage only, the study confirms a higher utilization amongst women $(20 \%$ more than men). In any case, the differences were always smaller than those reported in the literature for the general population.

It is also interesting to analyse in detail the influence of the patient's age on benzodiazepine consumption or prescription. Depending on whether comparisons are made of the ratio of patients with and without prescription, or on the basis of true consumption (DDD per 100 beddays), results can lead to conflicting conclusions. The rate of prescription increases from the age of 15 and it is nearly stable beyond 35 . However, when the utilization is expressed in DDD and weighted by the relative number of beddays, the overall consumption rises from the age of 15 up to $35-40$, then progressively decreases for higher ages. By distinguishing between hypnotic and anxiolytic use according to the ATC codes, our results clearly show that the consumption of hypnotics, weighted by the number of beddays and, subsequently, by the number of users at different ages, remains fairly stable beyond the age of 35 . Consequently, the observed peak of benzodiazepine consumption is mainly due to the high consumption of anxiolytic benzodiazepines by patients aged 35 to 50 . This finding also emphasizes the poor indicative value of data when overall consumption of benzodiazepines in hospitals refers only to mean age and sex of patients. Moreover, results must be carefully interpreted when classifications of benzodiazepines in terms of hypnotics or anxiolytics are made. All benzodiazepines possess to some extent the two properties and, in practice, anxiolytic benzodiazepines are often used for their hypnotic effects. Never- 
theless, our finding seems to be confirmed by consumption data observed with patients having received only a once a night prescription and by the parallelism between these data and those obtained according to hypnotic ATC codes.

It is obvious that the utilization of benzodiazepine is ward-dependent. Unfortunately, the design of the present study did not allow the assessment of rational or irrational prescription patterns. Comparison of benzodiazepine consumption per ward or type of ward, between hospitals, would be a valuable exercise to assess prescription patterns. On the other hand, large variations of consumption within and between wards, as shown in the present study, demonstrate that comparisons of benzodiazepine consumption between hospitais need to take into account the specific circumstances of each institution.

The method used to estimate the number of inpatients initiated in benzodiazepine usage after discharge is questionable because it is based on one user category (non-users at admission but users up to hospital discharge). It was found that roughly $6.8 \%$ of the admitted patients initiated a benzodiazepine usage during admission. This figure is high when compared to other results (1.6-2\%) reported in the literature [7 8]. It reflects the high benzodiazepine consumption in Belgium. It also raises questions about benzodiazepine prescription habits in the hospital and their role in inducing medium- or longterm usage and subsequent dependence. Nevertheless, our findings are only indicative; they have to be viewed within the limits of a retrospective study conducted inside the hospital.

Regarding other aspects of the study, the ATCDDD methodology was found to be appropriate and quite suitable despite existing differences between a few DDD's and PDD's. However, when utilization patterns are analysed, the combination of DDD data and prescription data is required to achieve a better understanding.

\section{Conclusion}

The main objectives of the present study were to establish a chart of benzodiazepine consumption and to determine the influence of patient-related and hospital-related parameters on their use. When considering the influence of patient sex, patient age and type of ward, the results showed that the utilization of benzodiazepines in the hospital was different from the use in general practice. This kind of drug utilization review is a potentially valuable tool for discussions with physicians and Pharmacy and Therapeutic Committees when trying to change prescription habits and to promote a more rational use of drugs in the hospital. In fact, more comparative studies with standardized methodologies are definitely needed to understand and assess the mechanisms of prescription patterns.

In a follow-up of the present study, action has been taken in the hospital to make physicians and nurses more perceptive to benzodiazepine prescription and to their possible role and capacity in inducing benzodiazepine consumption habits. Oral communications were presented and later an internal information bulletin was distributed to nursing and clinical staffs. No internal policies on benzodiazepine use have been established but simple guidelines were recommended.

- Whenever possible, look for alternative therapies with special regard to psychotherapy and information.

- In any case, individualize the benzodiazepine prescription and avoid ward prescription habits.

- Favour the "as needed" scheme to systematic repeated administrations.

- Inform the patient about benzodiazepine prescription and utilization.

- Assess regularly the need for benzodiazepine prescription.

\section{References}

1 Balter MB, Manheimer DI, Mellinger D, Uhlenhuth EH. A cross-national comparison of anti-anxiety per sedative drug use. Curr Med Res Opin 1984;8 Suppl 4:5-20.

2 Ansseau M. The pharmacological treatment of anxiety. Rev Med Liege 1988;43:80-91.

3 Le Goc I, Feline A, Frebault D, Le Bras P, Caquet R. Characteristics of benzodiazepine consumption in a Department of Internal Medecine. Encephale 1985;11:1-6.

4 Ruiz I, Offermanns I, Fuentes P, Castillo M. Utilization of benzodiazepines in Chile during 1982-1986. Eur I Clin Pharmacol 1989;37:139-43.

5 Fleischhacker W, Barnas C, Stuppack C. Benzodiazepines: utilization and patterns of use in a university hospital. Pharmacopsychiatry 1989;22:111-4.

6 Shan K, Nolan JA, Turner P, Jackson S. Prescription of benzodiazepines in a London teaching hospital. I $\mathrm{R}$ Soc Med 1990;83:306-7.

7 Edwards C, Bushnell JL, Ashton CH, Rawlins MD. Hospital prescribing and usage of hypnotics and anxiolytics. Br J Clin Pharmacol 1991;31:190-2.

8 Surendrakumar D, Dunn M, Roberts C C. Hospital admission and the start of benzodiazepine use. BM] 1992;304:881.

9 Vandel S, Nezelof S, Bonin B, Dominique Mesnage A, Bertschy $G$, Jacquet $M$, et al. Consumption of benzodiazepines in a university hospital centre. Encephale 1992; 18:401-5.

10 Anatomical Therapeutic Chemical (ATC) Classification Index including Defined Daily Doses (DDDs) for plain substances. Oslo: World Health Organization, 1993. 